\title{
Role of Urinary Calcium and Creatinine Ratio in Assessing Bone Resorption in Lepromatous Leprosy.
}

\author{
Akhter $S^{1}$, Jaigirdar $\mathrm{MQH}^{2}$, ${ }^{*}$ Mahmud $\mathrm{MM}^{3}$, Haque $S^{4}$, Habib $\mathrm{RB}^{5}$
}

\begin{abstract}
Bony changes in lepromatous leprosy are one of the causes of deformity and disability. Fasting calcium and creatinine ratio in urine is used as a bone resorption marker in a number of diseases such as hyperthyroidism, osteoporosis, multiple myeloma, paget's disease and sarcodosis. In lepromatous leprosy assessment of bone resorption might be done with that marker. To assess the role of fasting urinary calcium and creatinine ratio as a marker of bone resorption in patients with lepromatous leprosy. A case control study was conducted on 28 patients diagnosed as lepromatous leprosy and 28 age-matched healthy control. The participants who fulfilled all inclusion and exclusion criteria were studied by measuring fasting urinary calcium and creatinine level as well as observing $X$-rays of both hands and feet of affected individuals. The mean age of cases $38.1 \pm 14.2$ years and $38.9 \pm 12.9$ years was in control group. Male - female ratio was 3.6: 1. It was observed that $10.7 \%$ leprosy patients showed urinary $\mathrm{Ca} / \mathrm{Cr}$ ratio $>0.20(0.13 \pm 0.12)$ and $10.7 \%$ healthy control showed urinary $\mathrm{Ca} / \mathrm{Cr}$ ratio ratio $>0.20$ (mean $\pm S D 0.11 \pm 0.7$ ). the difference was not statistically significant $(p>0.05)$. X-ray finding was positive in $14.3 \%$ leprosy patients and none of the
\end{abstract}

1. Dr. Saima Akhter, Lecturer, Department of Forensic Medicine, Dhaka Medical College Hospital, Dhaka, Bangladesh

2. Dr. Md. Qamrul Hassan Jaigirdar, Professor, Department of Dermatology and Venereology, Bangabandhu Sheikh Mujib Medical University, Dhaka, Bangladesh

3. *Dr. Md. Mostaque Mahmud, Assistant Professor, Department of Dermatology and Venereology, Bangabandhu Sheikh Mujib Medical University, Dhaka, Bangladesh. E-mail: drmstq@yahoo.com, 01711100552

4. Dr. Shawana Haque, Assistant Professor, Department of Biochemistry, CARe Medical College Hospital, Dhaka

5. Dr. Rahat Bin Habib, Consultant, Tungipara UHC, Gopalganj.

${ }^{*}$ For correspondence control group. That difference was not significant statistically $(p>0.05)$. there was no relation between raised urinary $\mathrm{Ca} / \mathrm{Cr}$ ratio and positive findings of bone resorption on $x$-rays among the leprosy cases.

Keywords: Leprosy, urinary calcium creatinine ratio, bone resorption, lapromatous leprosy

\section{INTRODUCTION}

Leprosy is caused by Mycobacterium leprae, discovered in 1873 by Hansen at Bergen in Norway. It is believed to be transmitted via droplets from the nose and mouth, through close contact with a person affected by the disease who has not received treatment. The bacillus multiplies slowly and it can take up to 20 years before symptoms appear. Leprosy primarily affects the skin, peripheral nerves, the nasal tissues, the bones and can damage the eyes and testes. Delayed treatment can result in physical and sensory disability; including damage to fingers and toes, contractures, inability to close the eyelids and blindness which often lead to social isolation. ${ }^{1}$

Bony changes usually occur in Leprosy patients of long duration. About $80 \%$ of joint lesions are in the metatarsophalangeal joints of the foot or in theinterphalangeal joints of the hands and feet. Bone changes are divided into specific and secondary changes. Specific bone changes are caused by direct invasion of the bones by $M$. leprae causing granulomatous lesions seen as focal areas of rarefaction on X-rays. Nasal bone changes have described asspecific for lepromatous leprosy infection. ${ }^{2}$ Incidence of bony changes in Leprosy found $15 \%, 29 \%$ and $95 \%$ in different studies. ${ }^{3,4,5}$ In the small bones of lower limbs these changes include honeycombing, pseudocysts, enlarged nutrient foramina, and areas of bone destruction leading to concentric cortical erosion and thinning to collapse of bone.

Secondary bone changes are caused by destruction of nerve supply as well as vascular changes, trauma and secondary infection contribute to non-specific changes. The changes may be of four types: distal absorption of the digits, 
osteoarthritis, osteomyelitis,osteoporosis. ${ }^{6}$ Histologically, these lytic bone lesions present foamy macrophages with numerous bacilli, few lymphocytes, epitheloid cells and Langerhans giant cells. Osteoporosis is the second most common sign in patients with leprosy. It is thought to be due to high bacillary load and or reaction to an active lesion in the secondary area or due to immobilization and disuse atrophy. Testicular atrophy and subsequent low levels of testosterone contribute to generalized osteoporosis in males usually in patients with lepromatous leprosy. ${ }^{7}$ Motor denervation is sometimes associated with absorption of the cancellous bone and the development of a concentric type of bone atrophy. It affects both the length and width of bone. Osteoporosis mainly causes vertebral fractures, intertrochanteric fractures and colles fractures. ${ }^{8}$ Leprotic deformities are more common in males, usually after 40 years of age. Secondary changes are more common in Lepromatous leprosy patients.Bone resorption is well documented in Leprosy patients by radiological studies. Various radiological studies have shown bone resorption in leprosy patients usually involve limbs, alveolar bones and face. Archeological studies have found bone resorption in skeleton of leprosy patients. ${ }^{9,10}$

Very few biochemical studies have been done to evaluateboneresorption in leprosy patients with conflicting results. Calcium metabolism was studied in 47 patients with borderline or lepromatous leprosy. ${ }^{11}$ This was measured by serum total and ionized calcium, phosphorus, creatinine, total alkaline phosphatase, parathyroid hormone, 25-hydroxy vitamin D, and 1,25-dihidroxy vitamin D; calcium and total hydroxyproline, two important bone resorption markers were determined in urine. Although all values were within the normal ranges, lepromatous leprosy patients had lower total calcium, higher alkaline phosphatase, and higher urinary hydroxyproline than borderline leprosy patients.

Progression of bone disease may still occur even several years after having completed specific treatment for leprosy, meaning such treatment is necessary, but that is not sufficient to cure the bone lesions. ${ }^{12} \mathrm{~A}$ study was done to evaluate the therapeutic effect on oral administration of risedronate in male osteoporotic patients with leprosy.It had shown that oral administration of risedronate apparently prevented vertebral fractures by increasing lumber BMD and caused a significant reduction in urinary cross linked N-telopeptides of type 1 collagen (NTX), a marker of bone resorption. So treatment modality can certainly be changed to some extent by adding calcium supplement and anti- resorptive therapy with Bisphosphonates to prevent deformity resulting from bone resorption. Therefore, our honest effort has been made to evaluate bone resorption by measuring urinary calcium and creatinine level in lepromatous leprosy patients who are gravely suffered by mainly secondary bony changes and compared to controls.

\section{MATERIAL AND METHOD}

Clinically suspected LL patients were taken to panel of expert for confirmation and then detailed history taking and clinical examination were done and recorded. Then slit skin smear was done in all patients to confirmed the multibacillary leprosy. Then informed written consent was taken and all bacteriologically positive patients were included in the study procedure. Skin biopsies for histopathology were done in case of highly suspected B.I negative patients.

28 age and sex matched apparently healthy persons without any history of leprosy was included in this study procedure ascontrol group. Objective and purpose of this study was explained to the participants and then informed consent was obtained from them before initiation of the study. A detailed family history and medical examination were performed at screening stage for all participants. Controls were chosen from attendants of patients, staffs of BSMMU. After thorough physical examination, urinary calcium/creatinine was done as investigative procedure. As $\mathrm{x}$-ray is hazardous to health this procedure was done in selected controls whose urinary $\mathrm{Ca} / \mathrm{Cr}$ was $>0.20$. Questionnaire was filled up like LL patients. $5 \mathrm{ml}$ of random urine sample was collected after 14 hours of fasting from the diseased and control individuals in a clean, sterile glass bottle.Urinary calcium concentration was measured by an automated chemistry analyzer using the O-cresolphthaleincomplexone method with the calcium-C test. Urinary creatinine was analyzed by the same chemical analyzer using the standard Jaffe kinetic reaction with picric acid.Urinary calcium/creatinine $(\mathrm{mg} / \mathrm{mg})$ was calculated as fasting urinary calcium $(\mathrm{mg} / \mathrm{dl})$ excretion divided by fasting urinary creatinine excretion $(\mathrm{mg} / \mathrm{dl})$. A normal reference interval for the urinary calcium $(\mathrm{mg} / \mathrm{dl})$ : urinary creatinine $(\mathrm{mg} / \mathrm{dl})$ ratio is $<0.20$. Values exceeding 0.20 was found in patients with hypercalciuria indicating resorption process in bone. 


\section{RESULTS}

A total of 28 cases and 28 controls were enrolled in that study. Cases of LL were considered as group I and apparently healthy controls were considered as group II.

Table I shows majority of $10(35.7 \%)$ patients belonged to age $\leq 30$ years, in group I and $8(28.6 \%)$ healthy control in group II. The mean age was found $38.1 \pm 14.2$ years in group I and $38.9 \pm 12.9$ years in group II. There are no difference in age of two groups.

Table I: Distribution of cases and control according to age.

\begin{tabular}{|c|c|c|c|c|c|}
\hline \multirow[t]{2}{*}{ Age (years) } & \multicolumn{2}{|c|}{ Case $\mathrm{N}=28$} & \multicolumn{2}{|c|}{ Control $N=28$} & \multirow[t]{2}{*}{$P$ value } \\
\hline & $\mathrm{n}$ & $\%$ & $\mathrm{n}$ & $\%$ & \\
\hline 30 & 10 & 35.7 & 8 & 28.6 & \multirow{7}{*}{$0.826^{\mathrm{ns}}$} \\
\hline $31-40$ & 6 & 21.4 & 7 & 25 & \\
\hline $41-50$ & 8 & 28.6 & 6 & 21.4 & \\
\hline $51-60$ & 2 & 7.1 & 5 & 17.9 & \\
\hline$>60$ & 2 & 7.1 & 2 & 7.1 & \\
\hline Mean \pm SD & \multicolumn{2}{|c|}{$38.1 \pm 14.2$} & \multicolumn{2}{|c|}{$38.9 \pm 12.9$} & \\
\hline Range (years) & \multicolumn{2}{|c|}{56} & \multicolumn{2}{|c|}{50} & \\
\hline
\end{tabular}

${ }^{\mathrm{ns}}=\mathrm{P}$ value non significant

Table II shows the male out-numbered female. About $79 \%$ cases were male as well as in control group.

Table II: Distribution of cases and control according to sex.

\begin{tabular}{|l|c|c|c|c|c|}
\hline \multirow{2}{*}{ Sex } & \multicolumn{2}{|c|}{ Case $\mathrm{N}=28$} & \multicolumn{2}{c|}{ Control N=28 } & P value \\
\cline { 2 - 6 } & $\mathrm{n}$ & $\%$ & $\mathrm{n}$ & $\%$ & \multirow{2}{*}{$1.000^{\mathrm{NS}}$} \\
\hline Male & 22 & 78.6 & 22 & 78.6 & \\
\hline Female & 6 & 21.4 & 6 & 21.4 & \\
\hline Male to female ratio & \multicolumn{2}{|c|}{$3.67: 1$} & \multicolumn{2}{|c|}{$3.67: 1$} & \\
\hline
\end{tabular}

ns= $\mathrm{P}$ value non significant

Table III shows the urinary calcium and creatinine ratio. There was no significant difference in urinary calcium and creatinine ratio of case and control group ( $\mathrm{p}$-value $>0.05$ ).

Table III: Distribution of cases and control by urinary calcium creatinine ratio

\begin{tabular}{|c|c|c|c|c|c|}
\hline \multirow{2}{*}{$\begin{array}{l}\text { Calcium/Creatinine } \\
\text { ratio }\end{array}$} & \multicolumn{2}{|c|}{ Case $\mathrm{N}=28$} & \multicolumn{2}{|c|}{ Control $N=28$} & \multirow[t]{2}{*}{$\mathrm{P}$ value } \\
\hline & $\mathrm{n}$ & $\%$ & $\mathrm{n}$ & $\%$ & \\
\hline$\leq 0.20$ & 25 & 89.3 & 25 & 89.3 & \\
\hline$>0.20$ & 3 & 10.7 & 3 & 10.7 & \\
\hline Mean \pm SD & \multicolumn{2}{|c|}{$0.13 \pm 0.12$} & \multicolumn{2}{|c|}{$0.11 \pm 0.07$} & $0.449 \mathrm{~ns}$ \\
\hline Min-max & \multicolumn{2}{|c|}{$0.01-0.54$} & \multicolumn{2}{|c|}{$0.01-0.27$} & \\
\hline Range & \multicolumn{2}{|c|}{0.53} & \multicolumn{2}{|c|}{0.26} & value non \\
\hline
\end{tabular}

significant 
Table IV shows the mean fasting urinary calcium level was 13 in cases and it was 9.3 in controls but the difference was not significant statistically ( $\mathrm{p}$-value $>0.05$ ).

Table IV: Distribution of cases and control fasting urinary calcium.

\begin{tabular}{|l|c|c|c|}
\hline Fasting urinary calcium & Case $\mathrm{N}=28$ & Control N=28 & P value \\
\hline Mean \pm SD & 13.013 .5 & 9.311 .45 & $0.273^{\text {ns }}$ \\
\hline Min-max & $0.04-45$ & $1.1-60.7$ & \\
\hline Range & 44.96 & 59.6 & \\
\hline
\end{tabular}

${ }^{\mathrm{ns}}=\mathrm{P}$ value non significant

Table $\mathrm{V}$ shows the distribution of cases and control on $\mathrm{x}$-ray findings. Positive $\mathrm{x}$-ray finding was found in $14.3 \%$ cases and $3.6 \%$ in control.

Table V: Distribution of cases and control on x-ray finding.

\begin{tabular}{|c|c|c|c|c|c|}
\hline \multirow[t]{2}{*}{$\mathrm{x}$-ray findings } & \multicolumn{2}{|c|}{ Case $(n=28)$} & \multicolumn{2}{|c|}{ Control $(\mathrm{n}=28)$} & \multirow[t]{2}{*}{$\mathrm{P}$ value } \\
\hline & $\mathrm{n}$ & $\%$ & $\mathrm{n}$ & $\%$ & \\
\hline Positive & 4 & 14.3 & 1 & 3.6 & $0.35^{\mathrm{ns}}$ \\
\hline negative & 24 & 85.7 & 27 & 96.4 & \\
\hline
\end{tabular}

${ }^{\mathrm{ns}}=\mathrm{P}$ value non significant

\section{DISCUSSION}

This case control study was done for early detection of bone resorption by measuring fasting urinary calcium/creatinine ratio in Lepromatous leprosy patients. A total of 28 cases of LL patients (newly diagnosed, old and or treated) along with 28 age and sex matched healthy controls were included in this study who attended the outpatient department of Dermatology \& Venereology of Bangabandhu Sheikh Mujib Medical University (BSMMU) and Leprosy and Tuberculosis Control Institute of Mahakhali. The study period was from August 2014 to August 2016. Patients of LL were confirmed by history, clinical examination followed by conclusive investigations of slit skin smear and skin biopsy for histopathology.

The present study showed that the mean age was $38.1 \pm 14.2$ in group 1 and $38.9 \pm 12.9$ years in group 2 (in healthy controls). The difference was not statistically significant $(\mathrm{P}=$ 0.826 ) between two groups. The youngest patient in this study was 10 years old boy and the oldest was 65 years old. The maximum number of patients who showed bone changes in this study belonged to 20 to 65 years of age. In a Study the youngest patient of Lepromatous Leprosy was 12 years old and the oldest was 75 years old. The maximum number of patients 13 (18.57\%) who showed bone changes in that study belonged to the $40-49$ years of age group, whereas the least number of patients $2(2.87 \%)$ belonged to the 10-19 years age group. ${ }^{13}$

In this study it was observed that $78.6 \%$ patients were male and $21.4 \%$ were female. Male female ratio was 3.6:1, which indicates lepromatous leprosy is predominant in male subject. In a similar study $56(80 \%)$ patients were male and $14(20 \%)$ were female with a male: female ratio was $4: 1$. Ishida et al (1997) showed $238(46 \%)$ patients were male with LL and 139 (27\%) patients were female, which clearly indicates male predominance among the LL cases. ${ }^{14}$ These studies closely resemble the present study. Eighty percent of people in Bangladesh live in rural areas. Patients of LL came to Dermatology and Venereology department of BSMMU and TB and Leprosy control institute of Mahakhali from different rural areas. In contrast, patients of LL were few who came from urban as well as from affluent society. The study showed 21 patients (75\%) were from rural areas and 7 (25\%) from urban areas. 13 (46.4\%) healthy controls who participated in this study from rural areas and $15(53.5 \%)$ were from urban areas. The difference was statistically significant $(\mathrm{P}=0.028)$.In this study 14 (50\%) patients had duration of illness $\leq 1$ year and $14(50 \%)$ patients had $>1$ year. None of the patients had disease duration more than 3 years. As a result, only $3 \mathrm{LL}$ $(10.71 \%)$ patients showed urinary $\mathrm{Ca} / \mathrm{Cr}$ ratio $>0.20$. 
Another 4 (14.28\%) LL patients showed flexion deformity of interphalangeal joints of right hand and erosion of distal phalanges of right foot, lucent lesion in medullary cavity at proximal phalanx of right hand, Osteoarthosis and lytic area in medial aspect of proximal phalanx of left hand. A study among 70 leprosy patients where most of the patients had the disease for more than 10 years and were in the cured category, but all the patients had permanent residual deformities. Bone resorption is an early event in leprosy and is frequently already present at diagnosis. ${ }^{15}$ In this study $2 \mathrm{LL}$ patient $(7.14 \%)$ presented with urinary $\mathrm{Ca} / \mathrm{Cr}$ ratio $>0.20$ and one LL patient $(3.57 \%)$ presented with lucent lesion in medullary cavity at proximal phalanx of right hand on X-ray when they were first diagnosed as cases of Lepromtous Leprosy. Urinary calcium excretion corrected for creatinine was used as a marker of bone resorption in LL patients in this study. From the present study, it was observed that only 3 LL patients (10.7\%) showed urinary $\mathrm{Ca} / \mathrm{Cr}$ ratio $>0.20($ Mean $\pm \mathrm{SD} 0.13 \pm 0.12)$ and 3 healthy controls $(10.7 \%)$ showed urinary $\mathrm{Ca} / \mathrm{Cr}$ ratio $>0.20 \quad($ Mean \pm SD $0.11 \pm 0.7$. The difference was not statistically significant $(\mathrm{P}>0.05)$ between two groups. There was a study where urinary $\mathrm{Ca} / \mathrm{Cr}$ ratio was also used as a bone resorption marker. In that study, it was observed that there was a statistically significant increase in mean value of urinary calcium/ creatinine (0.13 Vs 0.09$)$ in cases as compared to controls. ${ }^{16}$ Another study showed urinary hydroxyproline, which was used as a bone resorption marker markedly elevated in LL patients. ${ }^{17}$ On the contrary, another study among 24 lepromatous leprosy patients where urinary calcium, urinary creatinine and urinary excretion of hydroxyproline were within normal range. This study closely resembles the present study. ${ }^{18}$

Some investigatorsmentioned that bone resorption has been well established by radiographic studies. In this present study $\mathrm{x}$-ray findings were positive in 4 patients (14.3\%) out of 28 cases and none of the control groups showed positive findings on $\mathrm{x}$-ray. The difference was not statistically significant $(p>0.05)$ between two groups. This study showed flexion deformity of interphalangeal joints of right hand in 1 patient (25\%),Lucent lesion in medullary cavity at proximal phalanx in 1patient (25\%), Osteoarthosis in 1 patient $(25 \%)$ and lytic area in medial aspect of proximal phalanx of left hand in 1 patient (25\%). In the present study, all the 4 patients (14.3\%) showed non-specific bone changes. On the contrary, another group of researchers showed specific bone changes were more prevalent among the LL and BB types of leprosy (100\%). ${ }^{19}$ But other researchersshowed $75 \%$ specific bone changes, $100 \%$ non-specific and $75 \%$ osteoporosis among the LL cases. In another study there was non-specific bone changes among $26.7 \%$ of LL cases. In a similar study it was observed that $46 \%$ of multibacillary patients were belonged to bone changes. In other studiesthat figure was $11 \%$ and there were more patients belonged to the multibacillary group. ${ }^{20}$ Multidrug therapy has limited impact on bone loss. ${ }^{21}$ In this study, itwas observed, 2 LL patients (14.3\%) who received treatment $<1$ year among the 14 patients, had urinary $\mathrm{Ca} / \mathrm{Cr}$ ratio $>0.20$ and $1 \mathrm{LL}$ patient $(14.3 \%$ ) who received no treatment among 7 patients, had urinary $\mathrm{Ca} / \mathrm{Cr}$ ratio $>0.20$. The mean was found $0.12 \pm 0.10$ in first group, $0.18 \pm 0.17$ in second group and $0.95 \pm 0.06$ in third group who received treatment more than one year and urinary $\mathrm{Ca} / \mathrm{Cr}$ ratio was $<0.20$. The $\mathrm{P}$ value was .001 which was statistically significant between the groups. This present study also showed flexion deformity of IP joints of right hand and erosion of distal phalanges of right foot in $1 \mathrm{LL}$ patient $(50 \%)$,osteoarthrosis in another patient among 2 patients who got treatment for $<1$ year. Lytic area in medial aspect of proximal phalanx of left hand was found in 1 patient $(100 \%)$ who got treatment for more than 1 year, and 1 patient $(100 \%)$ had lucent lesion in medullary cavity at proximal phalanx of left hand, who was newly diagnosed. Ina cohort study of 105 newly-diagnosed adult multibacillary leprosy patients admitted for treatment between 1990-1992..2 The patients were surveyed until 1999. Progression of bone resorption (BR) in cured leprosy patients was observed up to 8 years after release from MDT. Twenty three percent of the patients were found to have acralresorption. BR was found to be associated with male sex, grade of disability at diagnosis with other deformities and with the occurrence of four or more lepra reactions.A positive correlation was tried to find out between raised urinary $\mathrm{Ca} / \mathrm{Cr}$ ratio and positive $\mathrm{x}$-ray findings (both hands and feet) indicative of bone resorption among the LL patients. But such finding was not observed in this study. The 3 LL patients who showed raised urinary $\mathrm{Ca} / \mathrm{Cr}$ ratio $>0.20$ did not show any bone changes on $\mathrm{x}$-ray. Similarly, all the $4 \mathrm{LL}$ patients who showed bony changes on $\mathrm{x}$-rays had normal urinary $\mathrm{Ca} / \mathrm{Cr}$ ratio. A study was conducted among 47 borderlines and LL patients where calcium and hydroxyproline were measured in urine and total subperiosteal diameter and medullary cavity were measured on an $\mathrm{x}$-ray of the hand of all patients. ${ }^{23}$

\section{CONCLUSIONS}

This study was carried out for the first time in Bangladesh to detect early bone resorption in LL patients by measuring urinary calcium/creatinine ratio. This bone resorption marker was not used in LL patients widely over the world. Sufficient data and information were unavailable. The test 
was also done among healthy controls. But no statistically significant difference was found between cases and controls from this study. Furthermore, this test was not well correlated with resorption findings on $\mathrm{x}$-ray. May be it is due to bone resorption closely related with long duration and severity of the disease.

\section{REFERENCES}

1. Srinivasan $\mathrm{H}$. The problem and challenge of disability and rehabilitation in leprosy. Asia Pacific Disability Rehabilitation Journal. 1998;9(2):48-54.

2. Andersen JG, Manchester K, Ali RS. Diaphysealremodelling in leprosy: a radiological and palaeopathological study. International Journal of Osteoarchaeology. 1992 Sep;2(3):211-9.

3. Kanaji A, Higashi M, Namisato M, Nishio M, Ando $\mathrm{K}$, Yamada H. Effects of risedronate on lumbar bone mineral density, bone resorption, and incidence of vertebral fracture in elderly male patients with leprosy. Leprosy review. 2006 Jun 1;77(2):147-53.

4. Illarramendi X, Carregal E, Nery JA, Sarno EN. Progression of acral bone resorption in multibacillary leprosy. Actaleprologica. 2000;12(1):29-37.

5. MacMoran JW, Brand PW. Bone loss in limbs with decreased or absent sensation: ten year follow-up of the hands in leprosy. Skeletal radiology. 1987 Aug 1;16(6):452-9.

6. Faget GH, Mayoral A. Bone changes in leprosy: a clinical and roentgenologic study of 505 cases. Radiology. 1944 Jan;42(1):1-3.

7. Ishikawa A, Ishikawa $S$, Hirakawa M. Osteoporosis, bone turnover and hypogonadism in elderly men with treated leprosy. Leprosy review. 2001 Sep;72(3): 322-9.

8. Andersen JG, Manchester K, Roberts C. Septic bone changes in leprosy: a clinical, radiological and palaeopathological review. International Journal of Osteoarchaeology. 1994 Mar;4(1):21-30.

9. Choudhuri H, Thappa DM, Kumar RH, Elangovan $\mathrm{S}$. Bone changes in leprosy patients with disabilities/ deformities (a clinico-radiological correlation). Indian journal of leprosy. 1999;71(2): 203-15.

10. Chhabriya BD, Sharma NC, Bansal NK, Agrawal GR. Bone changes in leprosy. A study of 50 cases. Indian journal of leprosy. 1985;57(3):632-9.

11. Moonot P, Ashwood N, Lockwood D. Orthopaedic complications of leprosy. The Journal of bone and joint surgery. British volume. 2005 Oct;87(10): 1328-32.
12. de Lagrán ZM, Arrieta-Egurrola A, González-Pérez R, Soloeta-Arechavala R. Bone complications in a patient with lepromatous leprosy. Actas Dermosifiliogr. 2009 Jan 1;100(07):615-7.

13. Balachandra AS, Hombal A, Sudhakar R, Varna NM. Radiological changes in the hands and feet of leprosy patients with deformities. Journal of Clinical and Diagnostic Research. 2011 Aug 1;5(4):703-7.

14. Kumar WJ, Kothari SY, Swamy MK. Deformities and bone changes in leprosy. IJPMR. 2014;25:13-7.

15. Ribeiro FB, de Assis Pereira F, Muller É, Foss NT, de Paula FJ. Evaluation of bone and mineral metabolism in patients recently diagnosed with leprosy. The American journal of the medical sciences. $2007 \mathrm{Nov}$ 1;334(5):322-6.

16. Swathi M, Rao R, CR WD. Evaluation of bone resorption markers in leprosy. International Journal of Clinical and Diagnostic Research 2004; vol. 2, no.2.

17. Mautalen CA, Vega EM, Einhorn TA. Are the etiologies of cervical and trochanteric hip fractures different?. Bone. 1996 Mar 1;18(3):S133-7.

18. Vidal MC, Bottasso OA, Lehrer A, Puche RC. Altered calcium-binding ability of plasma proteins as the cause of hypocalcemia in lepromatous leprosy. International journal of leprosy and other mycobacterial diseases. 1993 Dec 1;61:586-.

19. Paira SO, Roverano $S$. The rheumatic manifestations of leprosy. Clinical rheumatology. 1991 Sep 1;10(3): 274-6.

20. Olmos JM, Hernández JL, Martínez J, Castillo J, Valero C, Pajares IP, Nan D, González-Macías J. Bone turnover markers and bone mineral density in hypertensive postmenopausal women on treatment. Maturitas. 2010 Apr 1;65(4):396-402.

21. Kanaji A, Higashi M, Namisato M, Nishio M, Ando $\mathrm{K}$, Yamada H. Effects of risedronate on lumbar bone mineral density, bone resorption, and incidence of vertebral fracture in elderly male patients with leprosy. Leprosy review. 2006 Jun 1;77(2):147-53.

22. Bührer-Sékula $S$, Illarramendi X, Teles RB, Penna ML, Nery JA, Sales AM, Oskam L, Sampaio EP, Sarno EN. The additional benefit of the ML Flow test to classify leprosy patients. Actatropica. 2009 Aug 1;111(2):172-6.

23. Barbieri RR, Sales AM, Illarramendi X, Moraes MO, Nery JA, Moreira SJ, Sarno EN, Machado AD, Bozza FA. Diagnostic challenges of single plaque-like lesion paucibacillary leprosy. Memorias do Instituto Oswaldo Cruz. 2014 Nov;109(7):944-7. 